\title{
Investigación en Terapéutica clínica: Ensayos clínicos con medicamentos
}

\author{
Research in Therapeutics. Clinical trials with drugs
}

José Antonio Durán Quintana

Facultad de Medicina. Universidad de Sevilla. Hospital Universitario Virgen Macarena. Servicio de Farmacología Clínica. Sevilla.

La investigación biomédica mediante ensayos clínicos ofrece rasgos propios: finalidad concreta, aplicabilidad inmediata y efectuarse sobre seres humanos. Está sometida al ordenamiento jurídico, y en nuestro país específicamente al Real Decreto $223 / 2.004$. Se puede definir al ensayo clínico como una prueba científica de un fármaco, aceptada por el enfermo y amparada por la ley. En cualquier caso, siempre deben respetarse los postulados éticos básicos: autonomía, justicia, beneficencia y no maleficencia. Los protagonistas de un ensayo clínico son: promotor, monitor, investigador y los sujetos del ensayo, todos ellos ensamblados por las autoridades sanitarias. Para su aprobación, el ensayo clínico necesita la existencia de un protocolo específico. El principal problema en la realización de ensayos clínicos es conseguir la coordinación de todas las personas e instituciones participantes en el mismo.

Palabras clave: ensayos clínicos, bioética, investigación con medicamentos.
Biomedical research via clinical trials offers certain features: defined aim, immediate applicability, and implementation on human beings. It is subject to the legal system - in Spain, specifically to the Real Decreto 223/2.004. The clinical trial can be defined as the scientific testing of a drug, accepted by the patient and safeguarded by law. In all cases, the basic ethical postulates of independence, equity, virtue, and non-harmfulness must always be respected. The participants in a clinical trial are the promoter, the supervisor, the researcher, and the subjects under trial - all convened by the health authorities. The approval of a clinical trial requires the existence of a specific protocol. The main problem in carrying out clinical trials is to achieve the co-ordination of all the people and institutions taking part.

Key words: clinical trials, bioethics, drug research.

\section{INTRODUCCIÓN}

La investigación en el campo de la terapéutica con medicamentos comparte con la realizada en otras áreas de conocimiento el afán de avanzar en el saber consolidado que se tiene. Sin embargo, la investigación farmacológica mediante ensayos clínicos pre-

Correspondencia:

José Antonio Durán Quintana

Facultad de Medicina. Universidad de Sevilla

Sevilla

E-mail: maduran@us.es senta la particularidad de ser aplicada. Eso significa que la búsqueda emprendida ofrece rasgos propios: tiene una finalidad concreta y necesita respuestas que puedan ser aplicadas de inmediato. Además, sin poderse desprender de lo anterior, destaca que su realización se lleva a cabo sobre seres humanos con voluntad y capacidad de decisión propias.

El que los sujetos de la investigación con medicamentos dispongan de libre albedrío incorpora un componente ético de primera magnitud, que no puede soslayarse de ninguna forma. Es más, acaba convirtiéndose en su principal ingrediente y en el firme sobre el que asienta todo el edificio de esta variante tan particular de investigación. De hecho, está admi- 
tido universalmente que resultaría inválida cualquier investigación biomédica en el hombre (con o sin medicamentos), por científicos que fueran sus planteamientos, diseño y objetivos, si no se cumplieran rigurosamente los postulados éticos vigentes.

En tal sentido conviene destacar que las personas incluídas en un ensayo clínico (sanos o enfermos) son, cada uno de ellos, protagonistas individuales del mismo. Su papel es unipersonal e irrepetible. No es verdad, aunque así lo parezca, que constituyan un grupo formado por la simple adición de individuos. Muy al contrario, representan la coincidencia individualizada en un determinado tiempo y lugar de varias personas que acaban constituyendo un grupo. Que dicho grupo humano forme parte de un ensayo clínico y que en tal situación funcione como receptor de un medicamento o de un placebo, es una circunstancia que no invalida lo anterior.

\section{ENTORNO LEGISLATIVO}

En el ordenamiento jurídico español se han ido sucediendo a lo largo del tiempo una serie de disposiciones legales sobre los ensayos clínicos, que han conformado una verdadera escalera legislativa. Merced a ella, cada medida legal constituye un peldaño que permite comprender tanto el fundamento de lo legislado hasta ese momento como la justificación del ascenso al escalón superior.

La primera de estas disposiciones data de hace más de 25 años; se trata del Real Decreto 944/1.978, por el que se regulan los ensayos clínicos de productos farmacéuticos. Algunos años después se publicó la Ley 25/ 1.990 del Medicamento, que dedica íntegro su Título III a los ensayos clínicos. En el que destaca la reconversión de los Comités de ensayos clínicos (ya existentes en el Real decreto antes citado) en los llamados Comités éticos de investigación clínica, con lo que ello tiene de realce del componente ético de la investigación con medicamentos.

El paso siguiente fue el Real Decreto 561/1.993, por el que se establecen los requisitos para la realización de ensayos clínicos con medicamentos. Durante toda la década posterior a su publicación este documento legislativo ha sido un instrumento muy sólido y eficaz, cubriendo todas las necesidades sobre esa particular forma de investigación clínicoterapéutica que es la realizada con fármacos.

La incorporación a la realidad española de la legislación europea (en concreto, la Directiva 2001/20/CE del Parlamento Europeo y del Consejo) ha obligado a la publicación de un nuevo real decre- to que sustituya al del año 1.993. Se trata del Real Decreto 223/2.004, por el que se regulan los ensayos clínicos con medicamentos. En él, además de las incorporaciones legislativas europeas antes señaladas, se recogen las realidades que sobre este campo de la investigación han ido surgiendo en nuestro país a lo largo de los once últimos años.

\section{DEFINICIÓN DE ENSAYO CLÍNICO}

Se trata de una definición difícil de hacer, entre otras razones porque puede plantearse desde perspectivas diferentes. Las más importantes serían la epidemiológica y la puramente legal.

La óptica epidemiológica permite asegurar que un ensayo clínico es «el estudio experimental de la eficacia y tolerabilidad de los fármacos en pacientes». Incluso hay epidemiólogos más restrictivos, que consideran insuficiente o poco preciso el concepto anterior. Para ellos, sólo tienen consideración de ensayos clínicos los estudios controlados, aleatorizados y a doble ciego. Parece una definición demasiado técnica, en exceso especializada, y que deja al margen de ella aspectos tan trascendentes como el bioético. Una cosa es aceptar que tales estudios se conceptúen como el "patrón oro" en la evaluación de la terapéutica con medicamentos en el ser humano, y otra distinta asumir que sólo son eso.

Si se encaran desde un punto de vista legalista, la mejor definición será la que recoja el Real Decreto 223/2.004. Dice así en su Artículo 2: «Ensayo clínico: toda investigación efectuada en seres humanos para determinar o confirmar los efectos clínicos, farmacológicos y/o demás efectos farmacodinámicos, y/o detectar las reacciones adversas, y/o estudiar la absorción, distribución, metabolismo y excreción de uno o varios medicamentos en investigación con el fin de determinar su seguridad y/o su eficacia». Es una definición que tiene, entre otros inconvenientes, ser demasiado extensa, lo que la hace poco práctica.

Con una óptica personal, intentando aunar la funcionalidad (brevedad) y todos los componentes del ensayo clínico (ético, científico-médico y jurídico), nuestra definición de ensayo clínico sería: «Una prueba científica de un fármaco, aceptada por el enfermo y amparada por la ley».

\section{ASPECTOS ÉTICOS}

En el Artículo 3 del Real Decreto 223/2.004 se establece con claridad que «Los ensayos clínicos se realizarán en condiciones de respeto a los derechos 
del sujeto y a los postulados éticos que afectan a la investigación biomédica con seres humanos. Los postulados éticos básicos son cuatro: autonomía, justicia, beneficencia y no maleficencia.

El principio de autonomía expresa el respeto por las personas, en este caso concreto por las participantes como sujetos en un ensayo clínico. La forma práctica de plasmar este respeto es informar al sujeto sobre el ensayo clínico y solicitarle su participación voluntaria en el mismo. Hay que tener consideración especial en quienes tengan disminuida su autonomía (menores, pacientes psiquiátricos, etc.).

El principio de justicia busca que todos los sujetos participantes tengan las mismas oportunidades de recibir el tratamiento que se está ensayando, que se supone téoricamente superior al utilizado hasta entonces. La garantía que se cumple este postulado consiste en efectuar una selección aleatoria de los pacientes.

El postulado ético de beneficencia asegura que el nuevo tratamiento (el que se está probando en el ensayo clínico) presenta una adecuada razón beneficio/riesgo. Este postulado exige para su aplicación que exista una buena fundamentación científica previa del ensayo que se quiere efectuar.

El objetivo del postulado de no maleficencia consiste en no hacer mal a las personas, ni aún cuando lo soliciten. En tal sentido, llevar a cabo un ensayo clínico sin validez científica es un ejemplo claro de incumplimiento de este principio ético. De ahí se deduce que las mejores garantías de su cumplimiento, son: buena justificación del estudio, diseño metodológico riguroso y la inclusión de un número suficiente de sujetos para poder extraer conclusiones.

\section{PROTAGONISTAS DEL ENSAYO CLÍNICO}

En el Real Decreto 223/2.004 aparecen una serie de definiciones, entre las que se encuentran cuatro que corresponden a los protagonistas principales de la investigación clínica con medicamentos. Son los siguientes:

Promotor: Individuo, empresa, institución u organización responsable del inicio, gestión y/o financiación de un ensayo clínico.

Monitor: Profesional capacitado con la necesaria competencia clínica, elegido por el promotor, que se encarga del seguimiento directo de la realización del ensayo. Sirve de vínculo entre el promotor y el investigador principal, cuando éstos no concurran en la misma persona.

Investigador: Médico o persona que ejerce una profesión reconocida para llevar a cabo investigaciones en razón de su formación científica y de su experiencia en la atención sanitaria requerida.

Sujeto del ensayo: Individuo que participa en un ensayo clínico, bien recibiendo el medicamento en investigación, bien como control.

Es evidente que cada uno de estos protagonistas tiene una función definida, que se lleva acabo cuando el ensayo se pone en marcha. Sin embargo, la relación entre ellos no es igual en todos los casos. Así, por ejemplo, el promotor no contacta en ningún momento con los sujetos del ensayo; igualmente, cada vez es más infrecuente que el investigador se relacione directamente con el promotor. En consecuencia, debe existir un elemento común ensamblador a todos ellos. Su justificación se refuerza por la posibilidad de que surjan situaciones de conflicto que demandan resolución. Ese elemento son las autoridades sanitarias, que a través de sus sistemas de Inspección revisan los documentos, instalaciones, archivos y cualquier otro componente que se considere relacionado con el ensayo clínico.

\section{PROTOCOLO DE UN ENSAYO CLÍNICO}

Atendiendo a criterios diversos cabe distinguir diferentes tipos de ensayos clínicos. Todos ellos presentan en común el necesitar para su aprobación un Protocolo, entendiendo como tal «el documento donde se describen los objetivos, el diseño, la metodología, las consideraciones estadísticas y la organización de un ensayo». Como se observa, lo común a cualquier investigación clínica.

Aunque la existencia de un protocolo es condición indispensable para la realización de un ensayo clínico (se puede considerar la columna vertebral del mismo), se necesitan algunos requisitos más para su autorización por parte de las autoridades sanitarias. En efecto, junto a la preceptiva solicitud - dirigida a la Agencia Española de Medicamentos y Productos Sanitarios - el promotor debe aportar otros documentos, como la hoja de información para los sujetos del ensayo, el expediente del medicamento en investigación (cuando proceda) y la justificación del pago de las tasas previstas.

Un Medicamento en investigación es una «forma farmacéutica de una sustancia activa o placebo que se investiga o se utiliza como referencia en un ensayo clínico». Conviene recordar que este concepto abarca a los fármacos nuevos, no comercializados aún, y a los ya comercializados en algunas circunstancias; concretamente, cuando se utilicen o combi- 
nen (en la formulación o en el envase) de forma diferente a la autorizada, y cuando se utilicen para una indicación no autorizada o para obtener más información sobre un uso autorizado.

La autorización de las autoridades sanitarias es condición necesaria, pero no suficiente, para la realización de un ensayo clínico en nuestro país. Previamente, el promotor debe obtener también un dictamen favorable de un Comité Ético de Investigación Clínica (que puede ser único en los ensayos multicéntricos) y la conformidad de la dirección de cada uno de los centros donde se realizará el ensayo.

\section{CONSIDERACIONES ECONÓMICAS}

La financiación de un ensayo clínico corre a cargo del promotor. En la gran mayoría de los casos esa figura corresponde a un laboratorio fabricante de medicamentos; al hacerlo, busca calidad en la investigación, eficiencia, rapidez y rentabilidad en la inversión monetaria. En un reducido número de casos quien promueve el ensayo es una entidad sin ánimo de lucro: Sociedad científica, grupo de investigadores, etc.; en tales ocasiones se pretende ampliar el conocimiento, en algún aspecto concreto, sobre la utilización clínica del fármaco en estudio.

Los aspectos económicos relativos al ensayo clínico deben quedar reflejados en un contrato entre el promotor y cada uno de los centros donde se lleve a cabo el ensayo. En él constará el presupuesto inicial del ensayo, especificando - entre otras gastos -los indirectos que aplicará el centro, los directos extraordinarios (los que no hubiera habido si el paciente no hubiera participado en el ensayo) y las compensaciones para los sujetos del ensayo y los investigadores. En la práctica, la firma de este contrato suele plantear dos clases de conflictos cuando se pretende efectuar un ensayo clínico: el primero, la indefinición de su naturaleza jurídica (¿contrato administrativo o privado, convenio de colaboración?, etc.); y el segundo, la incertidumbre respecto al tiempo en que la dirección del centro lo firmará (con el consecuente perjuicio para el promotor si se alarga más de lo razonable).

Cuando el ensayo clínico se realice con medicamentos en investigación el promotor es responsable de la contratación de un seguro de daños y perjuicios que, como consecuencia del ensayo, puedan resultar para la persona en que hubiera de realizarse. Esta garantía financiera cubrirá las responsabilidades del propio promotor, las del investigador principal y sus colaboradores, y las del centro donde se lleve a cabo el ensayo clínico.

\section{PROBLEMAS EN LA GESTIÓN}

Por minuciosa y actual que sea cualquier legislación, la primera condición para su aplicación efectiva es la voluntad de cumplirla por parte de las personas e instituciones a las que afecta. Aún dándose este requisito, su cumplimiento en la práctica se ve interferido en numerosas ocasiones. Esta situación también ocurre en el proceso de desarrollo de un fármaco.

La publicación del R.D. 223/2.004 intenta superar una serie de limitaciones e inconvenientes que la experiencia ha mostrado durante los años de vigencia de su antecesor (R.D. 561/1.993). De todos ellos, la descoordinación era el que más repercutía en el calendario previsto para la realización del ensayo clínico.

El dictamen único en los ensayos multicéntricos, la aparición de un Comité Ético de Investigación Clínica de Referencia (organismo independiente que debe dictaminar sobre la idoneidad del ensayo clínico) y la fijación de plazos en que las solicitudes de los ensayos deben ser respondidas, son elementos que favorecerán y agilizarán la necesaria y deseable coordinación.

No conviene, sin embargo, echar las campanas al vuelo. Un dictamen favorable del Comité de Referencia y la autorización de la Agencia Española del Medicamento son dos de las condiciones necesarias para la realización de un ensayo clínico. Hay que contar con un tercer requisito: la conformidad del Centro donde se llevará a cabo, expresada mediante la firma de un contrato. En este requisito local, dependiente no sólo de la discrecionalidad de la Dirección del Centro, sino también de la legislación autonómica correspondiente, puede encontrarse un escollo que imposibilite una respuesta rápida, unívoca y generalizada en todo el territorio nacional. Sería deseable sensibilizar a las personas e instituciones responsables de la gestión sanitaria pública sobre la trascendencia del papel que les corresponde en este asunto.

\section{TRASCENDENCIA DE LOS ENSAYOS CLÍNICOS}

Desde un punto de vista clínico, la finalidad última de los ensayos clínicos es la obtención de los mejores patrones científicos y éticos que garanticen la existencia de medicamentos de calidad, seguros y 
eficaces. No obstante, les restan otras posibilidades que conviene no olvidar.

Así, el número y tipos de ensayos clínicos que se realizan en un país son indicadores sanitarios, que dan una idea aproximada sobre: la calidad de la asistencia sanitaria que se presta, el grado de desarrollo de la investigación clínica existente y la valoración científico-médica por parte de la industria farmacéutica.

Como cualquier otra intervención en el campo de la salud, también es posible medir el impacto que en ella tiene los ensayos clínicos. Entra otras cosas: proporcionan información necesaria para el registro de nuevos medicamentos, facilitan cambios en los hábitos de prescripción de los médicos y favorecen la introducción de medicamentos poco novedosos (efecto «siembra»).

Por otro lado, la práctica de ensayos clínicos por parte de los médicos conforma mentalmente en ellos una variante de cultura médica, la que se puede denominar cultura del ensayo clínico. Y lo hace por tres razones: por un lado, facilita la formación metodológica necesaria para valorar los fármacos que prescriben; por otra parte, justifica, posibilita y refuerza la investigación clínica que efectúan; finalmente, impregna de contenidos éticos todo su quehacer profesional, asistencial 0 investigador.

Consecuencia de lo anterior es que la práctica generalizada de ensayos clínicos, tanto en atención primaria como en especializada, se constituye en un elemento unificador de la medicina. Ello es posible porque se ha transformado de método (uno más de los disponibles) en fundamento, de instrumento local en comportamiento universal.

\section{BIBLIOGRAFÍA (consultada)}

1. Armijo JA, Adín J. Farmacología clínica: objetivos y metodología. En: Flórez J, Armijo JA, Mediavilla A, eds. Farmacología humana, $4^{\mathrm{a}}$ ed. Barcelona: Masson, 2003; 191-218.

2. Bakke OM, Carné X, García F. Ensayos clínicos con medicamentos. Fundamentos básicos, metodología y práctica. Barcelona: Doyma, 2004.

3. Baños J-E, Farré M. Principios de Farmacología clínica. Bases científicas de la utilización de medicamentos. Barcelona: Masson, 2002.

4. Durán JA. El ensayo clínico, elemento unificador de la medicina. Sevilla: Real Academia de Medicina, 1995.

5. Friedman LM, Furberg CD, DeMets DL. Fundamental of Clinical Trials. St Louis: Mosby, 1996.

6. Hulley SB, Cummings SR, Browner WS, Grady D, Hearst N, Newman TB, eds. Designing clinical research, 2nd edition. Philadelphia: Lippincott Williams \& Wilkins, 2001.

7. Pocock SJ. Clinical trials. A practical approach. Chichester: Wiley, 1991.

8. Real Decreto 223/2004, de 6 de febrero, por el que se regulan los ensayos clínicos con medicamentos (B.O.E. $\mathrm{n}^{\circ} 33,7$ de febrero de 2004).

9. Spilker B. Guide to clinical trials. New York: Raven Press, 1991. 